KAMILA ŁUCJAN

Maria Curie-Skłodowska University, Lublin

Departament of Cartography and Geomatics

k.lucjan@poczta.umcs.lublin.pl

\title{
Perception of the contents of animated maps
}

\begin{abstract}
Intense development of computer technology has taken place in the last several decades made it possible to cartographically present variability of phenomena in a dynamic way. As a result of using animation techniques in cartography there appeared new methods of presentation of changes, referred to as direct. Considering the character of the relation between display time and real time, two basic types of animated maps have been distinguished: temporal and non-temporal. Other criteria of classifying animation are the presence and level of interactivity and the technical criteria of production.

Regardless of the applied classification, perception of the contents of animated maps is one of the main issues, since using animation leads to a significant cognitive load specific for dynamic methods. Fast sequence of data and its quick disappearance can result in omission of some information because in the case of animated maps there is a higher risk of exceeding perception potential of users than in the case of static maps.

Higher efficiency of animated map perception can be achieved by applying methods of cognitive overload reduction determined through experimental research. The most important of them are: using control tools, directing attention with dynamically blinking lights, locating connected objects close to one another, using sound, adapting generalization level to the characteristics of moving images and accounting for the age and experience of map users.

Among more sophisticated solutions are such elements as so-called decay and a combination of static and animated map features in the form of semi-static animations.
\end{abstract}

Keywords: cartography, animated map, animation, perception

\section{Introduction}

For many years of the history of cartography the necessity to project a multi-spatial reality into a two-dimensional form has been one of the main problems of map making. The third dimension on a map is linked to the presentation of other features of phenomena (e.g. altitude a.s.I.), while the fourth dimension represents time. A number of indirect presentation methods have been developed to evoke an impression of three-dimensionality or dynamics. Dynamics of phenomena can be connected with a change of object location (its movement in space), or result from variability of qualitative or quantitative characteristics (state dynamics). Such types of dynamics can also appear together. It was only the development of computer tech- nology in the last few decade that created favorable conditions for the appearance of new, direct methods of cartographic presentations of variability of phenomena. Using computers facilitated the application of animation techniques to the presentation of dynamics. Despite intense development of various techniques of map elaboration, presentation of phenomena dynamics remains a significant and valid challenge for cartographers.

A. Koussoulakou and M.-J. Kraak (1992) notice that a cartographer can use three main methods of presentation of phenomena variability. On a single static map ${ }^{1}$ dynamics is presented indirectly using visual variables. With either of the other two solutions (series of

\footnotetext{
${ }^{1}$ Single maps include multiphase, balance and types.
} 
static maps or an animated map) visual variables are not used to present changes. While in the case of a series of static maps the time factor is deduced from the sequence of images presenting successive stages of phenomenon's development, animation allows perception of dynamics basing on the changing picture. Dynamic methods of presentation of variability are referred to as direct.

\section{Development of direct methods of presenting dynamics}

Until the 1960s film was the only method of direct presentation of time-spatial variability. The first movie maps presenting movement in a dynamic way were made in the United States in the 1920s. The period of World War II was especially significant for the development of animated maps. In 1940 Walt Disney Studios prepared, among others, a 30-second black and white newsreel. Its production required extensive labor and means, since the applied technology involved drawing each single frame separately, resulting in thousands of images for a single short film. The final film, however, was not particularly detailed or highly realistic regarding time and space. the dynamics of spatial relations. The author claimed that the popularity of animated images, achieved mainly because of Walt Disney Studio, should be exploited in cartography. Audiences became familiar with this type of medium and as a result its efficiency increased.

The first computer animation was generated by Edward Zajac from Bell Laboratories in New Jersey. It presented the location of a telecommunication satellite orbiting the Earth (fig. 1). Obstacles which the creators of first animations had to face are presented, among others, in the article Possibilities for computer animated films in cartography, published in "The Cartographic Journal” (B. Cornwall, A. Robinson 1966). The authors applied a mixed technology - at the stage of creating particular frames and projecting the animation they used computer equipment; to achieve a moving image the frames were filmed by a camera placed in front of the monitor.

Waldo Tobler's presentation of changes in Detroit population from 1970 was the first computer aided cartographic animation described in a scientific publication. Significant input into the development of animated maps was brought by Harold Moellering (1976), who presented road accidents in Detroit within the period of

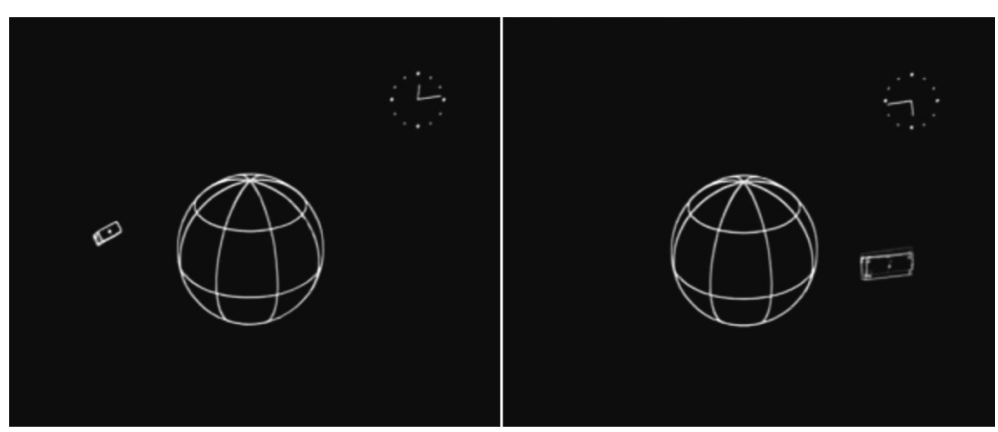

Fig. 1. Frames from the animation prepared by E. Zajac

First scientific articles on the possibility of applying film technology in cartography appeared in the mid-1950s. In Norman J.W. Thrower's Animated Cartography, published in 1959, the author analyzes fifty cartographic animations from 1936-1957 (M.W. Meksuła 1999). In his next article (1961) N.J.W. Thrower indicated the potential of animated maps used to illustrate three years. In $1980 \mathrm{H}$. Moellering constructed subsequent animated maps which presented the growth of the U.S. population between 1850 and 1970. He decided to use a new solution, which was later criticized - changing the viewer's perspective. The method which he applied was later developed in many studies (M. Harrower 2004). 
Development of technical aspects of preparing animations which took place in the following years made in possible to apply more and more advanced methods of presenting dynamics. A period of intense changes in computer hardware and software required for animation started over 40 years ago. At first the costs of animation production was extremely high. In mid-1970 s production of animations required the equipment worth several million dollars, and the work on a 30 " film lasted up to six months. The following decade brought about significant changes with the arrival of the personal computer and the development of peripheral equipment (monitors, digitizers, scanners) and software $^{2}$ (M.W. Meksuła 1999).

What was also important from the point of view of the author of animations was the development in the field of data gathering methods in the last 30 years. There appeared such media as a diskette, CD and then DVD and flash memory. Another turning point took place
Further development of computer equipment brought about systematic decrease of animation production costs, and thus its growing popularity. Today's technology provides favorable conditions for generating professional animated maps. It is also significant that computers became commonly available which created a large group of potential users of animated maps.

Also the rapid growth of the Internet technology in the last 20 years (mostly the appearance of WWW) has had considerable significance for cartography. Popularization of internet access and the emergence of more and more advanced technical solutions affected various aspects of the process of map creation. M. Harrower (2004) notes that the Internet offers new possibilities of distribution and increases map availability which results in higher demand for cartographic presentations. Additionally, WWW enables interactivity, which is especially important in the case of dynamic studies.
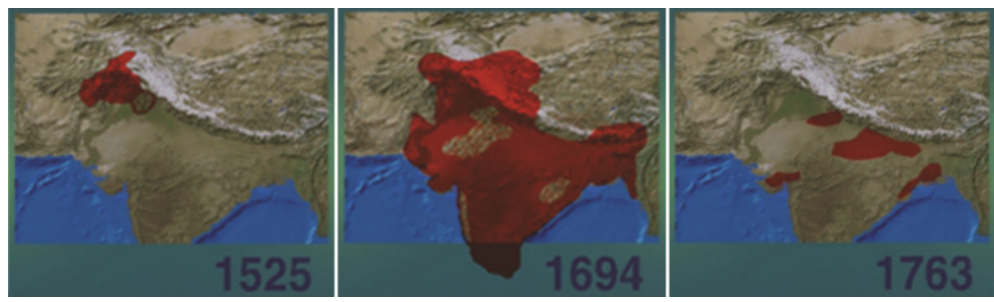

Fig. 2. Example of a temporal animation (selected frames) presenting the changing area of the Mogul Empire in $1500-1850$

when the working frequency of processors exceeded $200 \mathrm{MHz}$, and also with the introduction of standard formats of recording animations (MPEG, Quicktime).

The film industry brought considerable input into the development of computer animation. In 1983 Lucasfilm studio finished a short film presenting a virtual trip around San Francisco (Road to Point Reyes). Soon digital animation started to be used for special effects. Also now cinematography remains one of the main stimulators of development of computer animation, together with computer gaming industry and the military.

\footnotetext{
2 Animation software by companies such as Alias Research and Wavefront Technologies.
}

Growing interest in application of animation techniques in cartography, supported with widely understood technological development (film, TV, computer hardware and software, Internet) resulted in the creation of new forms of direct presentation of the variability of phenomena. Many types of cartographic animations are distinguished depending on the specific character of presented data as well as on other criteria (e.g. intended purpose of the presentation).

\section{Types of animated maps}

Character of the relation between display time and real time is one of the more important criteria of animation classification. In 1993 

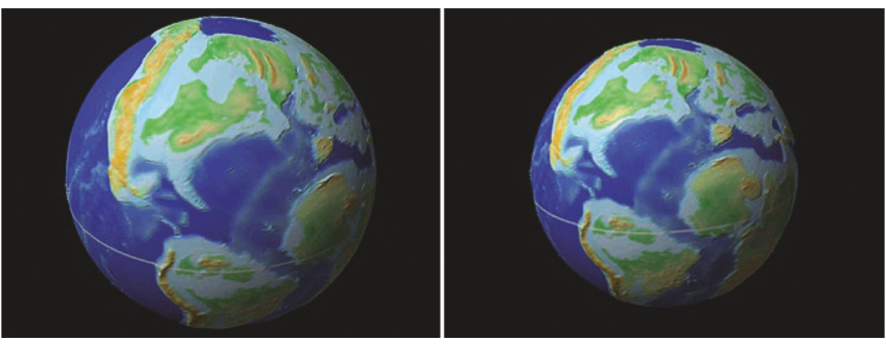

Fig. 3. Example of a non-temporal animation: the placement of continents in the late Cretaceous (about 80 million years ago)
D. Dransch divided animated maps into two major types: temporal and non-temporal (M.-J. Kraak, A. Klomp 1995).

Temporal animations (fig. 2) are characterized by a direct relation between "the time in which the animation is presented and the real time" (M.-J. Kraak, F. Ormeling 1998). They can illustrate both location dynamics and state dynamics.

Non-temporal animations show "changes caused by factors other than time" (M.P. Peterson 1996). One of the most popular non-temporal presentations is a so-called fly-through in which the viewer's perspective changes (fig. 3). Another solution applied in non-temporal animations is a successive build-up which can be executed by adding subsequent thematic layers, or by displaying selected contents to show a spatial trend (fig. 4).

Non-temporal animations are quite a wide category in which changing representations are the dynamic element. They can present the same data using, among others, different methods of presentation (choropleth map, isoline method, dot method), method of variable class intervals (fig. 5), or classes determined using various methods (fig. 6), as well as in various cartographic projections. Such studies illustrate the influence of the presentation method on the spatial image of a phenomenon.

P.J. Kowalski (2002) classified the methods of dynamic presentation using the criterion of the subject of transformation (animation). He applies the term "transformation" for changes of contents and "metamorphosis" for form changes. Transformation includes "conversion mirroring changes of location, size and characteristics of geographic objects", e.g. dynamic variants of classic methods of presentation (dynamic isolines, dynamic diagram). Methamorphoses are equivalent to non-temporal animations. Their dynamics does not result from reality changes in time, but from e.g. a change of scale and degree of generalization, cartographic projection, presentation method, or some of these factors together.

Another criterion of animated map classification is interactivity: presence or absence of control tools as well as the type of them. J.P. Ogao (2002) distinguished three types of animation

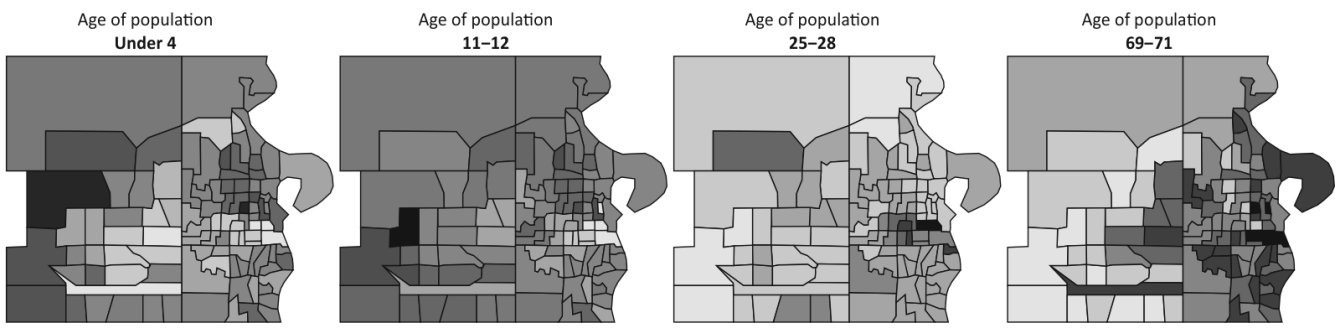

Fig. 4. Example of a non-temporal animation (selected frames) presenting the placement of various age groups in the city of Omaha (Nebraska) 

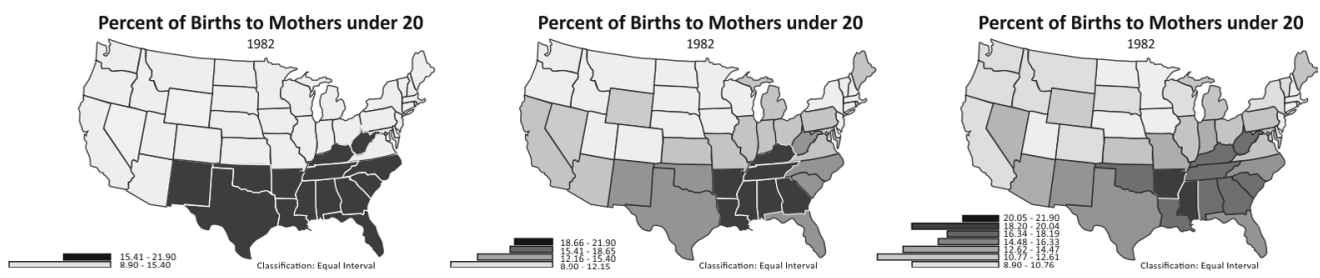

Fig. 5. Example of a non-temporal animation (selected frames) presenting how the number of choropleth map intervals affects the image of a phenomenon
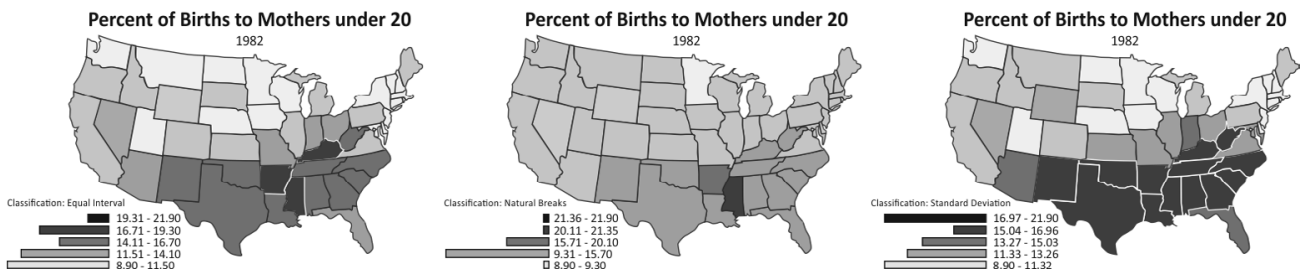

Fig. 6. Example of a non-temporal animation (selected frames) presenting how the image of a phenomenon affects the number of choropleth map intervals

by their level of interactivity. He considered the view only animations to be the most common type. As a rule they have no control tools, or have minimal interaction capability. The next type are interactive interface animations with such functions as forwarding and reviewing, pause and replay. Most advanced tools are offered in interactive contents animations which enable the user to interact with the presented contents with buttons, active legend, options of activating and de-activating layers etc.

The editing process of animated maps also involves selection of a graphic format. Considering the technical criterion of production, P.J. Gersmehl (1990) distinguished seven types of animation applied in cartography, which can be grouped in two main categories. The first of possible solutions is the frame-by-frame method in which each picture is constructed separately and connected with others into a single presentation. This method requires a large number of frames (M.P. Peterson 1995). Images are saved and played in raster formats such as Quicktime, MPEG or AVI, but files are considerably large, which makes their distribution difficult.

The second category of animation includes vector elaborations constructed using the tech- nique of key frames. Vector animations resemble the technique of film animation involving foil transparencies. Each frame of animation can be constructed of many layers. The constant elements in the background are common for individual frames, while changing objects move in the foreground. In more refined animation forms the elements of background and foreground move simultaneously. Objects can be subject to dynamics as a result of a procedure called tweening, which involves generation of a defined number of frames between key (basic) frames. The tweening technique, which includes changing object location as well as changing their color and shape, makes it possible to produce animation in the time shorter than in the case of the frame-by-frame technique (M.P. Peterson 1995).

Currently yet another animation technique is employed - the algorithmic method "in which the moving picture is generated basing on the information gathered in a database" (T. Opach 2006). Many cartographers consider this technique to be the future of animated maps (M.-J. Kraak, F. Ormeling 1998). However, regardless of the technical aspects of animation production it seems that at this stage of development of cartographic methods of presenting 
dynamics achieving appropriate level of efficiency of animated maps remains one of the main challenges.

\section{Cognitive limits in the perception of animated maps}

Since in the case of animated maps the risk of inefficient presentation of information is much higher than with static maps and because their production is very time-consuming, a lot of attention should go into the editing process to ensure that the contents is communicated with appropriate efficiency. Intense effort involved during the animation editing process requires that special attention must be paid to its communicative aspect. At the very beginning it should be decided if the animated map will allow the user to more effectively and correctly perceive presented contents than in the case of a static map. In other words it must be determined, if the specific character of presented contents justifies the application of a dynamic form of presentation (A. Koussoulakou, M.-J. Kraak 1992).

Most space-time processes can be presented on a traditional map. Selection of dynamic presentation is advisable when the presentation of some contents on a static map would be difficult or impossible. If the presentation aims to underline variability and fluency of phenomena, or to show certain spatial relations rather than particular data, animated maps turn out to be more appropriate (M. Harrower 2003). According to the rule of congruity, referred to, among others, by B. Tversky and co-author (2002), animation seems more suitable than a static map in the case of presenting variability. Employment of cartographic animation should be preceded with the understanding of its merits and limitations as well as with the awareness of the effect it can have on users.

Because of a significant variability of contents (rapid appearance and disappearance of signs), there exists a risk of overlooking some of the information displayed with the direct methods of presenting dynamics. Dynamics of the picture make the main objectives of map reading, such as evaluation of symbol size or reading names, difficult to execute. It is also probable that movement may have negative impact on the perception of changes in graphic variables. Therefore particular animation fra- mes should be properly generalized, both in the base layer as well as in the thematic layer of the presentation. Animated maps with too high level of detail may be difficult to perceive. Additional information "competes" with basic information for user's attention and increases the probability of overlooking important events during the animation.

At the current level of development of computer technology limitations accompanying the elaboration of animated maps result mainly from the perception capability of the user and only to a lesser extent from the quality of equipment or software. Because of the specific character of animated pictures (presence of movement, variability), there is an increased risk (compared to static maps) of exceeding the threshold of user's capability of processing information.

It is worth stressing that problems with reception of the contents of animated maps arise more from the difficulty with memorizing data and linking it with the existing knowledge than from the perception of current changes. If a map simultaneously presents many elements of contents (so-called complex information), with mutual relations between them, and if in addition there happen continuous changes of context, then in the case of limited time for perception there appears a danger of cognitive overload ${ }^{3}$. In such case the efficiency of the communication process can be significantly limited.

As noticed by P. Ayers et al. (2005), animations constitute a major challenge for memory structures of a human. Information contained on dynamic maps is elusive and if not repeated it remains in short-term memory ${ }^{4}$ for no longer that several seconds. For the purpose of the correct interpretation of current events, and to understand the whole animation, it is necessary that the user remembers the preceding

\footnotetext{
${ }^{3}$ Cognitive overload takes place when requirements of processing information exceed the capacity of cognitive system (R.E. Mayer, R. Moreno 2003).

${ }^{4}$ Three memory systems can be distinguished: sensory memory, short-term memory and long-term memory ( $\mathrm{T}$. Maruszewski 2002, P.G. Zimbardo 1999). The first stores the image received through senses for a very brief time (up to $0.5 \mathrm{~s}$.). Then the material can be transferred to short-term memory - the system of limited capacity (up to several elements of presented material) which stores information in the form of a direct interpretation of a sensory image. Long-term memory has theoretically unlimited capacity and length; the main difficulty in using it is to gain access to stored information.
} 
frames. To free short-term memory, some of the information must be immediately moved to long-term memory. Mutual relation between the above systems should be improved and the excessive need for short-term memory should be reduced (e.g. through proper design of user interface).

J.B. Morrison (2000, after M. Harrower 2003) defined four key issues linked with the perception of animated images: disappearance, attention, confidence, complexity. Research and practical activities aiming to improve the efficiency of animated maps focus on these issues.

\section{Methods of cognitive load reduction}

In order to overcome the cognitive overload resulting from the perception of animated maps, one of the following solutions can be applied:

1) animation structuralization by providing user instructions, division of the animated map into fragments, focusing user attention through commentary;

2) increasing the level of interactivity.

Application of solutions mentioned in the first point visibly increases the efficiency of conveying the contents. Through focusing user attention (commentary, filtering) they minimize e.g. the effort needed to find the elements of the contents necessary for the correct understanding of the whole communication.

One of the most simple strategies applied to properly direct attention is by using special dynamic signs in the crucial moments of animation. Blinking moving signs effectively draw user's attention, thus stressing the significance of the particular element of contents, but they have to be used moderately to avoid irritation and distraction. Also add-ons and sound hints help to properly direct user attention.

The issue of directing attention refers to the map itself as well as to the interface. Apparently the simpler the interface, the more time is spent on the main contents of the map. Animation interface should be possibly simplified, so that the effort necessary to understand it would not discourage the active use of the map.

A short introduction to the interface, preceding the presentation itself, is one of the possible solutions proposed to familiarize users with the animated map, and how to use it. Efficiency of instructions preceding the animation has been proven in experiments (R.E. Mayer et al. 2002). This strategy makes it possible to learn the tools needed for reading the map contents. It should be noted that users are less confident of knowledge obtained through animation than through static images (L.P. Rieber and M.W. Parmley 1995; J.B. Morrison 2000, after M. Harrower 2003).

In order to improve the efficiency of animation it is also advisable to divide it into parts (T.A. Slocum et al. 1990, M. Monmonier 1992; D.K. Patton and R.G. Cammack 1996, after M. Harrower 2007). R.E. Mayer and P. Chandler (2001), and also B.S. Hasler et al. (2006, after M. Harrower 2007) conducted research which showed that animation divided into parts is more efficient than a continuous presentation.

In the second group of solutions aiming to limit the cognitive load by increasing the level of interactivity there are presentation control tools, such as pause, speed change or looping. They allow individual adjustment of particular parameters to individual user's capability of perception, which significantly increases the chance of receiving information. M. Harrower (2007) claims that the option of looping is a necessary element of a well designer animated map, because users usually feel comfortable only after having watched the animation several times. Returning to earlier material helps to refresh short-term memory and integrate new information with the contents of long-term memory.

Referring to his own experience in editing and using animated maps as well as to the tests conducted in the preceding years, M. Harrower (2003) presents a series of solutions to basic problems concerning the perception of animated maps. Enabling the user to: a) watch the animation several times, b) pause the animation and follow changes frame by frame, c) individually control animation speed are simple actions which help to reduce the effect of rapid picture changes

Opinions on the efficiency of using interactivity in animated maps are generally positive. N. Andrienko et al. (2000) claim that the reception of animation is most efficient when the user can influence its flow and when spatial data can be analyzed in many different ways. Many authors stress the advantages of using control tools (A. Koussoulakou, M.-J. Kraak 1992; 
M. Monmonier, M. Gluck 1994; M.P. Peterson 1999), also to facilitate discovery of new spatial relations. B.S. Hasler et al. (2006, after M. Harrower 2007) maintain that interactivity can reduce the cognitive load during the reception of animation.

P. Ayers et al. (2005) present interesting conclusions summing up the results of research on the usage of control tools in animated maps. They suggest that increasing the level of interactivity stimulates the user to put more mental effort into the learning process, presence of control tools motivates active reception of the contents.

However, interactivity should not be treated as a universal method of overcoming problems connected with the perception of animated maps. Research of T.A. Slocum et al. (2004) suggests that the presence of control tools is beneficial when the user wants to concentrate on details, while non-interactive animations highlight general tendencies of phenomena and processes.

While preparing animated maps one should remember the crucial issue of the split-attention effect ${ }^{5}$ which appears when the material (e.g. the map and the legend) is located separately. The issue of split attention is considered to be one of the more important issues connected with elaboration and usage of cartographic animations (M.-J. Kraak et al. 1997, T. Midtbø 2001, M. Harrower and B. Sheesley 2005). Using the legend, or control tools, each time results in a loss of some part of the information presented in the map window. This difficulty can be overcome with pausing the presentation, but it not only eliminates the animated effect, but also focuses the attention of the user on the interface.

Summarizing the results of works in this field, R.E. Mayer (2001, after M. Harrower 2007) notices that communication is most efficient when the connected elements (images and their textual explanations) appear close to each other. In the opposite case the additional cognitive effort required to visually locate and connect data reduces the size of working memory. Thus the split-attention effect can reduce the efficiency of the learning process.

\footnotetext{
5 Split-attention effect takes place when the user "must mentally integrate separate information sources" (R.E. Mayer 2001, after M. Harrower 2007).
}

In order to reduce the split-attention effect it is advisable to join maps and legends into a visual whole and to use an audio temporal legend (M.-J. Kraak et al. 1997). Also R.E. Mayer and R. Moreno (2002) state that connected materials should be physically integrated (e.g. explanations placed not in the legend but directly on the map).

In the case of complex animated maps consisting of many components, there is a tendency to draw user attention to dynamic elements at the cost of static ones (T. Opach et al. 2014).

Sound can play an important role in reducing the cognitive load during the perception of animated maps. R.E. Mayer (2001, after M. Harrower 2007), basing on his research, formulated a rule of modality, according to which the perception of animation is more effective when it is accompanied with a commentary (spoken text), than in the case of written commentary appearing on the screen. The author lists three arguments supporting the use of audio commentary in animation: a) humans are naturally predisposed to two-channel perception (vision and sound), b) adding the second channel causes reduction of information processed in the first channel, c) the need to integrate visual and verbal representations stimulates active cognitive processing.

S. Kalyuga et al. (1999) also believe that using sound in animation can facilitate the learning process, however they claim that it is not because of a reduction of cognitive load or presentation complexity, but rather as a result of an increased capacity of effective working memory. The additional channel, such as in audio-visual presentations, increases the ability to process data. M. Harrower (2007) notices that the rule of modality can however be less efficient in the case of animated maps than for other types of animation. Because of a non-linear character of data presented on maps, application of sound turns out to be more complicated. Audio temporal legend is definitely easiest to prepare.

One of the more advanced methods of reducing cognitive load is using so-called decay, or gradual, delayed disappearance of signs representing particular objects or events. This method highlights them which is especially important in the case of momentary events which could remain unnoticed if represented according to the time scale. M. Harrower (2003) claims that time "exaggeration" is analogical to 
spatial exaggeration applied for symbolization on static maps (e.g. width of a road symbol is bigger than its width in the map scale).

Finally, the level of presentation complexity is also crucial from the point of view of the efficiency of communicating contents on animated maps. Although results of research on the effects of animation complexity on perception are ambiguous (T. Opach 2007), placing too much information can definitely lower the efficiency of the communication process. Effective animated maps are usually highly generalized, presenting only main tendencies and features.

Generalization of animation contents can take the form of filtering (e.g. through the presentation of a data sub-set) or combining data, preferably into two or three classes. Construction of the legend basing on the division of values into high, medium and low makes it easier to understand the contents. What's more, used colors should be easy to distinguish and remember (a small number of clearly distinctive colors), so that the user would not have to split his attention between the map and the legend. Number values of defined classes can be available on request, e.g. by clicking directly on the point or area sign on the map (M. Harrower 2003).

Specific characteristics of the medium (monitor or TV screen) and variability of animation form have big influence on sign design. To warrant high efficiency of contents communication, one should use appropriately large font sizes, sufficiently contrasting colors and adequately thick lines.

Basing on the research conducted in the last two decades R.E. Mayer and R. Moreno (2003) have developed the rules of design of efficient animated presentations. Most of these suggestions can be applied to preparation of animated maps:

1) if possible transfer the cognitive load from vision to sound - using sound seems especially efficient in the case of temporal legend;

2) enable pausing the presentation - it reduces the cognitive load, but eliminates the animation effect;

3) include a preliminary instruction - it can show how to use the interface and explain the signs used on the map;

4) regarding the often mentioned issue of cognitive load, during the process of animated map elaboration only the most important con- tents should be considered, especially in the base layer;

5) to direct user attention to important elements vivid colors and larger signs should be used, as well as special effects, such as e.g. blinking;

6) because of the split-attention effect discussed above, connected elements should be placed close to each other; in the case of animated maps this concerns mainly explanations of signs;

7) explanations should be displayed at the moment of signs appearance, making it easier to receive the contents;

8 ) in some cases redundancy is advisable it can be useful and improve the efficiency of contents communication, e.g. when temporal legend has both graphic and audio form;

9) contents of cartographic animations should be adapted to the perception capability and knowledge level of users; it is especially important in educational presentations.

An interesting solution which aims at improving the efficiency of animation is the proposal to combine the advantages of static and animated maps in the form of so-called semistatic animations. Experimental research conducted by A.S. Nossum (2012) showed higher efficiency of this method of presentation in relation to the traditional animated maps. A new type of animation designed by the author integrates the past, the present and the future. Semistatic animations continuously present the data for all the covered period (as on static maps) and simultaneously show data variability in time (as on animated maps). This solution mostly eliminates the issue of contents disappearance.

\section{Conclusions}

Progress in computer technology in the last several decades enabled an intense development of cartographic methods of direct presentation of variability of phenomena. With the introduction of more advanced technological solutions, there exists a clear need to complement the theoretical basis of presenting dynamic phenomena. A more profound understanding of specific characteristics of animated maps should be aimed at. Also, cognitive limitations related to animation should be considered 
during the editing process. It should be determined which contents can be presented most efficiently using animation and which presentation methods are effective and methodologically correct.

A series of solutions reducing the cognitive load and therefore improving the efficiency of reception of animated map contents can by indicated basing on recent research. Although it is difficult to point out the most important of them, two seem to be especially interesting and noteworthy. The first is the so-called decay, as well as other methods aiming at time "exag-

\section{Literature}

Andrienko N., Andrienko G., Gatalsky P., 2000, Supporting visual exploration of object movement. In: Proceedings of the Working Conference on Advanced Visual Interfaces AVI 2000, Palermo, Italy, May 23-26. New York: ACM Press, pp. 217-220.

Ayers P., Kalyuga S., Marcus N., Sweller J., 2005, The conditions under which instructional animation may be effective. International Workshop and Mini-Conference on Extending Cognitive Load Theory and Instructional Design to the Development of Expert Performance, 29 August, Heerlen, Netherlands. <https://www.ou.nl/Docs/Expertise/ OTEC/Nieuws/icleps\%20conferentie/Ayres.doc> (access 12.1.2017).

Cornwall B., Robinson A., 1966, Possibilities for computer animated films in cartography. "The Cartographic Journal” Vol. 3, No. 2, pp. 79-82.

Dransch D., 1993, Kartographische Animation. In: Kartographie und Geo-Informationssysteme, Grundlagen, Entwicklungsstand und Trends. „Kartographische Schriften” 1. Bonn: Kirschbaum Verlag, pp. 3-15.

Gersmehl P.J., 1990, Choosing tools: nine metaphors of four-dimensional cartography. "Cartographic Perspectives" no. 5, pp. 3-17.

Harrower M., 2003, Tips for designing effective animated maps. "Cartographic Perspectives" Vol. 44, pp. 63-65, <http://www.geography.wisc.edu/ harrower/CP_Harrower2004.pdf> (access 25.10.2005).

Harrower M., 2004, A look at the history and future of animated maps. "Cartographica" Vol. 39, no. 3, pp. 33-42, <http://www.geography.wisc.edu/ harrower/pdf/Animation_History.pdf> (access 29.11.2005).

Harrower M., 2007, The cognitive limits of animated maps. "Cartographica" Vol. 42, no. 4, pp. 349-357.

Harrower M., Sheesley B., 2005, Designing better map interfaces: A framework for panning and zooming. "Transactions in GIS" Vol. 9, no. 2, pp. 77-89. <http://www.geography.wisc.edu/ harrower/pdf/ Zanning.pdf> (access 29.11.2005). geration". This solution improves the process of mental linking of current information presented on an animated map with previous or subsequent frames, and with the existing knowledge of users. The other solution aiming to achieve a similar effect are semistatic animations, in which data covering the whole period are being displayed all through the presentation. Combining the functionalities of static and animated maps seems to be a promising direction in the development of cartographic methods of presentation of dynamic phenomena.

Hasler B.S., Kersten B., Sweller J., 2006, User control as an instructional method to reduce learners' cognitive load in transient animation. Annual Meeting of the American Educational Research Association (AERA 2006), April 6-11, San Francisco.

Kalyuga S., Chandler P., Sweller J., 1999, Managing split-attention and redundancy in multimedia instruction. "Applied Cognitive Psychology" Vol. 13, pp. 351-371. <http://tecfa.unige.ch/tecfa/teaching/ methodo/Kalyuga99.pdf> (access 12.1.2017).

Koussoulakou A., Kraak M.-J., 1992, Spatio-temporal maps and cartographic communication. "The Cartographic Journal" Vol. 29, no. 2, pp. 101-108.

Kowalski P.J., 2002, Kartografia dynamiczna - wyzwanie metodyczne i techniczne. In: Świat mapy - świat na mapie. „Główne problemy współczesnej kartografii 2002". Wrocław: Uniwersytet Wrocławski, Pracownia Atlasu Dolnego Śląska, Zakład Kartografii, pp. 137-154.

Kraak M.-J., Edsall R., MacEachren A.M., 1997, Cartographic animation and legends for temporal maps: exploration and or interaction. In: Proceedings of the 18th ICA/ACI International Conference. Stockholm. <http://www.geovista.psu.edu/publications/ MacEachren/Kraak_etal_97.PDF\#search=\%22cartographic\%20animation\%20kraak\%20edsall\%22> (access 25.10.2005).

Kraak M.-J., Klomp A., 1995, A classification of cartographic animations: towards a tool for the design of dynamic maps in a GIS environment, <http:// cartography.geog.uu.nl/ica/Madrid/kraak.html> (access 9.4.2013).

Kraak M.-J., Ormeling F., 1998, Kartografia, wizualizacja danych przestrzennych, Warszawa: Wydawnictwo Naukowe PWN.

Maruszewski T., 2002, Psychologia poznania - sposoby rozumienia siebie i świata. Gdańsk: Gdańskie Wydawnictwo Psychologiczne.

Mayer R.E., 2001, Multimedia Learning. Cambridge: Cambridge University Press. 
Mayer R.E., Chandler P., 2001, When learning is just a click away: does simple user interaction foster deeper understanding of multimedia messages? "Journal of Educational Psychology" No. 93, pp. 390-397.

Mayer R.E., Mathias A., Wetzell K., 2002, Fostering understanding of multimedia messages through pre-training: evidence for a two-stage theory of mental model construction "Journal of Experimental Psychology” No. 8, pp. 147-54.

Mayer R.E., Moreno R., 2002, Animation as an aid to multimedia learning. "Educational Psychology Review" Vol. 14, pp. 87-99. <https://ydraw.com/ wp-content/uploads/2012/04/Stop-Motion-Aids-Multimedia-Learning.pdf> (access 12.1.2017).

Mayer R.E., Moreno R., 2003, Nine ways to reduce cognitive load in multimedia learning. "Educational Psychologist" Vol. 38, no. 1, pp. 43-52. <http://www. uky.edu/ gmswan3/544/9_ways_to_reduce_CL. pdf $>$ (access 12.1.2017).

Meksuła M.W., 1999, Problemy kartograficznej prezentacji zjawisk dynamicznych na przykładzie map ludnościowych. Doctor thesis, Lublin.

Midtbø T., 2001, Perception of time variables on dynamic maps. In: Proceedings of the 20th International Cartographic Conference. 6-10 August, Beijing, China [CD-ROM].

Moellering H. 1976, The potential uses of a computer animated film in the analysis of geographical patterns of traffic crashes. "Accident Analysis \& Prevention" Vol. 8, pp. 215-227.

Moellering $\mathrm{H}_{\text {., }}$ 1980, The real-time animation of three-dimensional maps. "The American Cartographer" Vol. 7, no. 1, pp. 67-75.

Monmonier M., 1992, Authoring graphic scripts: experiences and principles. "Cartography and Geographic Information Science" Vol. 19, no. 4, pp. 247-60.

Monmonier M., Gluck M., 1994, Focus groups for design improvement in dynamic cartography. "Cartography and Geographic Information Science" Vol. 21, no. 1, pp. 37-47.

Morrison J.B., 2000, Does animation facilitate learning? An evaluation of the congruence and equivalence hypotheses. Doctor thesis, Department of Psychology, Stanford University.

Nossum A.S., 2012, Semistatic animation - integrating past, present and future in map animations. "The Cartographic Journal" Vol. 49, no. 1, pp. 43-54.

Ogao J.P., 2002, Exploratory visualization of temporal geospatial data using animation. <http://www. itc.nl/library/Papers/phd_2002/ogao.pdf\#search= $\% 22$ ogao\%20 Exploratory $\% 20$ visualization $\% 20$ of\%20temporal\%20geospatial\%20data\%20using\%20animation\%22> (access 7.7.2006).

Opach T., 2006, Z problematyki wykorzystania animacji w kartografii. „Polski Przegląd Kartograficzny” T. 38, nr 4, pp. 301-315.
Opach T., 2007, Eksperymentalne badania wpływu złożoności map animowanych prezentujących dynamikę zjawisk na ich percepcję. In: Współczesne problemy metodyki kartograficznej „Prace i Studia Kartograficzne" T. 1, Eds. M. Sirko, P. Cebrykow, Lublin, pp. 200-209.

Opach T., Gołębiowska I., Fabrikant S.I., 2014, How do people view multi-component animated maps? "The Cartographic Journal" Vol. 51, no. 4, pp. 330-342.

Patton D.K., Cammack R.G., 1996, An examination of the effects of task type and map complexity on sequenced and static choropleth maps. In: Cartographic Design: Theoretical and Practical Perspectives. Eds. C.H. Wood, P. Keller, Chichester, UK: Wiley, pp. 237-52.

Peterson M.P., 1995, Interactive and animated cartography. Upper Saddle River, New Jersey: Prentice Hall.

Peterson M.P., 1996, Between reality and abstraction: non-temporal applications of cartographic animation <http://maps.unomaha.edu/AnimArt/article.html> (access 25.4.2013).

Peterson M.P., 1999, Active legends for interactive cartographic animation. "International Journal of Geographic Information Science" Vol. 13, no. 4, pp. 375-83. <http://maps.unomaha.edu/AnimArt/ ActiveLegend/Peterson.pdf> (access 12.1.2017).

Rieber L.P., Parmley M.W., 1995, To teach or not to teach? Comparing the use of computer-based simulations in deductive versus inductive approaches to learning with adults in science. "Journal of Educational Computing Research” Vol. 13, pp. 359-374. <http://journals.sagepub.com/doi/pdf/10.2190/ M8VX-68BC-1TU2-B6DV> (access 12.1.2017).

Slocum, T.A., Robeson S.H., Egbert S.L., 1990, Traditional versus sequenced choropleth maps: An experimental investigation. "Cartographica" Vol. 27, no. 1 , pp. 67-88.

Slocum T.A., Sluter R.S., Kessler F.C., Yoder S.C., 2004, A qualitative evaluation of MapTime, a program for exploring spatiotemporal point data. "Cartographica" Vol. 39, no. 3, pp. 43-68.

Thrower N.J.W., 1959, Animated cartography. "The Professional Geographer" Vol. 11, no. 6, pp. 9-12.

Thrower N.J.W., 1961, Animated cartography in the United States. "International Yearbook of Cartography” Vol 1, pp. 20-30.

Tobler W.R., 1970, A computer movie simulating urban growth in the Detroit region. "Economic Geography" Vol. 46, pp. 234-240.

Tversky B., Morrison J. B., Bétrancourt M., 2002, Animation: Can it facilitate? <262http://serc.carleton. edu/files/NAGTWorkshops/visualize04/Tversky 2002. pdf\#search $=\% 22$ Animation $\% 3 A \% 20$ Can $\%$ 20lt\%20Facilitate\%3F\%22> (access 29.11.2005). Zimbardo P.G., 1999, Psychologia i życie. Warszawa: Wydawnictwo Naukowe PWN. 


\section{Internet sources}

http://maps.unomaha.edu/cartographic/animation/ Wausau2.MOV

http://www.youtube.com/watch?v=m8Rbl7JG4Ng

http://sydney.edu.au/arts/timemap/examples/map animation.shtml http://www.scotese.com/pg080anim.htm

http://maps.unomaha.edu/cartographic/animation/ NonTemporal/SpatTrend.MOV

http://maps.unomaha.edu/cartographic/animation/ NonTemporal/GenAnim.MOV

http://maps.unomaha.edu/cartographic/animation/ NonTemporal/Class_Anim.MOV 